\title{
A Study of Basic Strategies and Construction of College English Listening Training on Machine
}

\author{
Lihua Tang
}

College of Foreign Language Education of China West Normal University, Nanchong, Sichuan, China

*Corresponding author. Email: 16867933@qq.com

\begin{abstract}
The Internet provides convenience for college students to learn English online. At present, there are numerous strategies for English listening training, but the combination of English listening training and Internet needs to be studied more deeply and applied more widely. Built on practice, this paper explores the strategies and construction of English listening training under the network environment. It is possible to conclude that the improvement of English listening level is a long-term and gradual process, and also a process restricted by the comprehensive abilities of vocabulary, grammar, reading comprehension and knowledge.
\end{abstract}

Keywords: College English, Internet, Listening Training, Strategy.

\section{INTRODUCTION}

The Internet has created great conditions for online learning. Multimedia resources and multimedia computers provide convenience for simultaneous stimulation of multiple senses. There are more and more strategies for online English listening training. Recently, about 2,030,000 matching websites can be found by using the search keyword "listening strategy" at www.yahoo.com [1-2]. By searching the keyword "listening strategy" at www.sina.com.cn, 10800 matching websites were obtained. In the past, a large number of college students spent a lot of time and energy learning "deaf-mute English", which is obviously a problem of English learning strategies. Therefore, we should adhere to the principles of integration, authenticity, innovation and practicality. Learning from the results of various online listening training strategies we should construct scientific [3], practical and flexible basic English listening training strategies. It is an important task for the construction of College English listening website to meet the different requirements of College students.

\section{BASIC STRATEGIES AND CONSTRUCTION}

\subsection{Reading while listening}

In listening comprehension, we all think that attention and quick thinking are the key qualities. Generally speaking, the speed of thinking is four times that of speaking. In the case of solid thinking foundation, such a speed is easier to understand. However, under the traditional English listening training conditions, most of them adopt the form of collective listening. Learners are always thinking about what they are listening to [4]. If they don't understand, they may turn their attention to what they don't understand and forget to continue to listen to new content. Such repeated, they will be bored, tired, form psychological barriers, and even lose confidence in learning. Therefore, the construction of learning strategies while listening and reading in online courses can provide learners with good learning situations for autonomous listening and reading of English online (Figure 1). 


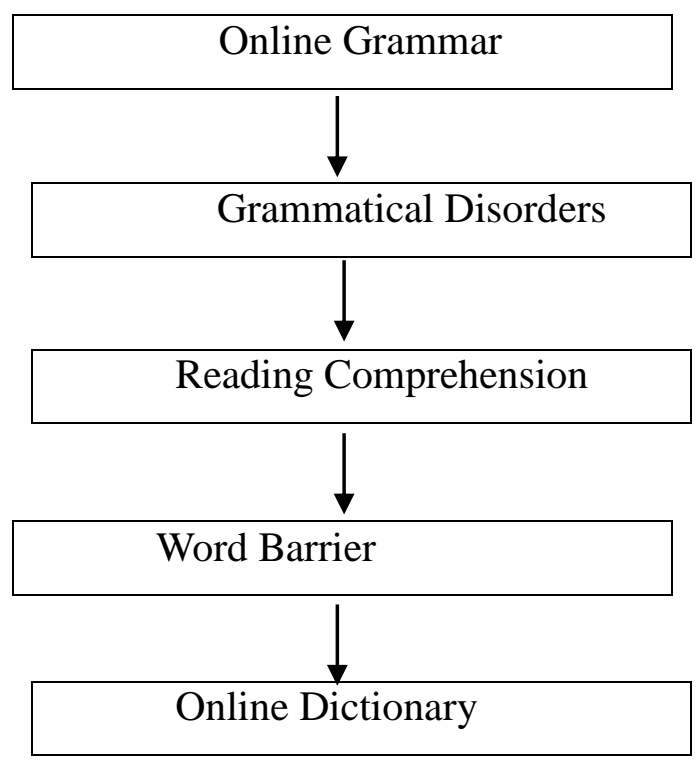

Figure 1 Barriers while listening

First of all, reading comprehension questions can improve learners 'attention. At the same time, providing course texts and supporting audio can reduce the difficulty of listening training and improve learners 'quick thinking ability and reading comprehension level. Online dictionaries (Jinshan Ciba) and online grammar help learners overcome learning difficulties at any time. Computers are never tired of being teachers. Students can ask the computer to remove the difficulties of new words [5], grammar and so on, then listen again. By this way, they can achieve the effect of listening by using reading comprehension questions to test the degree of understanding. This is a basic strategy for listening comprehension training.

\subsection{Listen and repeat}

Repeating is a powerful listening training strategy. Listening trainers repeat each passage precisely. Then immediately follow the speaker's speed and listen to a clip. Such repetition can achieve accurate repetition at the speed of hearing, and can gradually increase the length of repetition fragments. To construct the strategy of listening and repeating while reading on the internet, besides providing learning resources such as audio, text, online dictionary and online grammar, an online repeater is also needed. At present, the commonly used players such as Windows media player, Real player and so on do not have the function of repetition, nor do they have the function of synchronous text display. Although some programmers have developed special software such as repeater, it is not convenient to integrate with network courses. As Flash is one of the three swordsmen in the web page, it has powerful audio processing function. Therefore, Flash programming is chosen to develop a compact, flexible and practical repeater, which is more convenient for learners to apply in the network course of English listening.

Reading aloud is a good way of listening training. First, reading aloud helps memory. Second, it stimulates the development of vocal cord muscles through reading aloud. Third, it can help students gradually develop standard pronunciation, intonation and emotion by following the original repetition, speaking a foreign language in real situations with real foreigners, keeping up with the flow and speed of speech, imitating pronunciation and intonation. But in everyday situations, reading aloud from books without correct pronunciation guidance will inevitably lead to some errors, which will lead to some habitual errors in the long run [6]. Therefore, by setting up a special English column, downloading the audio and scripts of CRI Special English, VOA Special English programs, and synchronizing the scripts with the audio, students can read English directly with the world's top broadcasters. (Figure 2). 


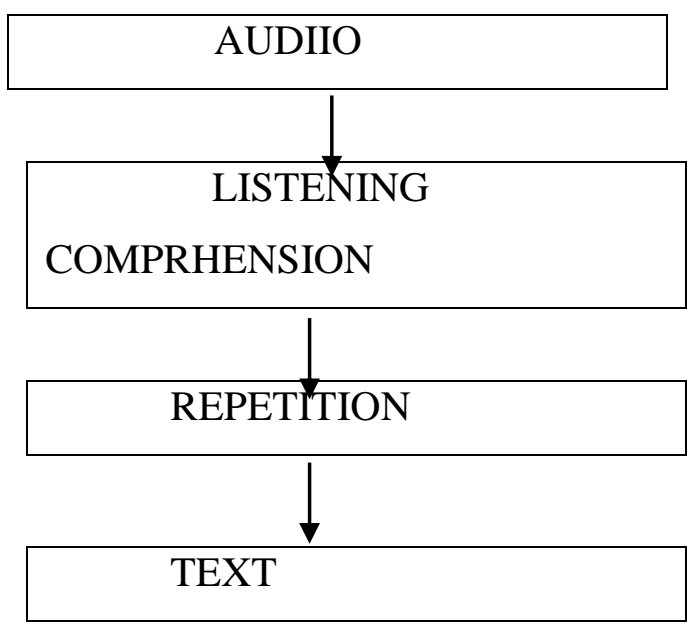

Figure 2 Functions of audio resources

\subsection{Writing while listening}

The founder of reverse English learning method is Mr. Zhong Daolong, professor of Nanjing Communication Engineering College. He began to work hard at English at the age of 45. It took him only about a year and a half to make progress from "unable to understand and speak" to being a translator. The key is to use dictation-based learning strategies. He listened to it all first, several times from beginning to end. He could not understand it at first, so he listened hard and divide the paragraphs and sentences into several parts. Listen carefully again and again in one sentence. He tried to make sure that a sentence consists of several words, and what role each word plays in the sentence. Every time he listens, he writes the words he understands one by one on paper or in the text box of a web page with a keyboard and arranges them into sentences. In the dictation process, English words are written by hand or input by keyboard continuously and it can form "motor memory" [7-8]. Continuous "listening, writing and speaking" of various words and sentence patterns can not only fix English knowledge, but also form a phonetic image and a higher level in the brain. As long as he hears the pronunciation of a word, the image of the word will immediately appears in his mind. As long as he sees the image of a word, it seems that the sound of the word immediately rings in his ear. Writing while listening is the most clumsy and effective method of English listening training. In order to reduce the difficulty of dictation, we can display part of the script text and hide part of it. According to the sound heard and the prompt of the display part, the keyboard is used to input word by word, and the correctness and speed of the input are displayed in real-time statistics. Real-time feedback of learning results improves the interesting and challenging of dictation. It is more convenient for learners to provide mouse and shortcut keys at the same time.

\subsection{Listen and talk}

The network can realize the functions of videoconferencing, voice chatting and so on. Virtual classroom can be constructed. This learning environment constructed by multimedia communication technology allows teachers and students in different places to hear and see each other. It can not only use real-time communication function to realize English distance teaching, but also use asynchronous communication function to achieve unprecedented teaching activities, such as asynchronous counseling, asynchronous discussion, etc. During the construction of the website [9-10], it provides audible, visual and Speakable voice chat rooms, so that learners can enter such a learning world at random and communicate directly with foreign English teachers, foreign friends and English learning enthusiasts. This is a good way of online language learning. Creating such a chat room requires some technical support. If it is difficult, it can be achieved by means of friendship links, such as using Crazy English chat room.

\subsection{Listening and doing exercises}

Randall's ESL Computer Audiology Laboratory does a good job in this area. We have made some references and improvements and applied them in practice.

\subsubsection{Pre-Listening Exercises}

Put forward thinking questions so that learners can clearly define the general objectives and tasks of listening training. Provide links to relevant websites, instruct learners to browse, understand relevant 
knowledge, list key words and sentence patterns for learners to understand or discuss with peers, lay a good thinking foundation for the next stage.

\subsubsection{Listening Exercises}

Play the voice and let students understand the general meaning. Students make choices and give them back in time. Open the corresponding listening script page and listen to the script again to remind learners to imagine putting their body and mind into the listening situation. Special attention is paid to key words and sample sentences. Listen while doing cloze test.

\subsubsection{Post-Listening Exercises}

Exchange learning experience and experience with peers and share learning outcomes. The content of listening test is classified according to easy, medium and difficult levels, reflecting the hierarchical teaching. Focus on the basis of thinking in the process of testing. Fully consider the systematization of knowledge. Current College English Listening Training strategy is to listen while doing, which combines listening with practice. It is step by step, from extensive listening to intensive listening, from discrimination to comprehension, from words to passages, from easy to difficult. Long-term practice has proved to be a good listening training strategy. However, due to the limitations of traditional classroom teaching and traditional speech lab, it has not been fully developed. This requires us to give full play to the advantages of the Internet and build the Internet. We need to construct online synchronous College English listening training strategies, develop online English listening question bank, examination and test system, and replace traditional voice with network voice room.

\subsection{Listen and translate}

For many Chinese students, interpretation means work and career. It is reported that in the past seven years, nearly 100,000 people have participated in the Shanghai Foreign Language Interpretation Qualification Certificate Examination. Only 5500BMany people have obtained qualification certificates for interpreting posts. Interpreters should also be certified. It requires systematic English skills, strong listening skills, strong Language lexical, syntactic, idiomatic skills. Therefore, the training of English interpreting is to strengthen and test learners' listening, vocabulary, grammar and other knowledge and abilities. It is a highly demanding synthesis. Therefore, some "interpreting" should be applied properly on the Internet. Learning strategies are also necessary to help college students improve their English listening and translation skills.

\subsection{Listen and watch}

Many people believe that it is reasonable to "go abroad for a month and learn English quickly". What you hear, see and use abroad is English. You must think of English, speak English, write English. You are in a real English study environment. Traveling All over America, Hong Environments English, etc. is the use of environmental teaching methods, the conversation and English listening, training course, shooting into TV series, real life oriented, and original juice. It presents the application of English in daily life with pure voice, normal flow teaching, through the repeated regeneration of the environment and the brain Stimulation. Natural English will blurt out in the face of similar environmental stimuli. And movie or Video can be built on the Internet. Provide students with the space for dictation scripts, and communicate with them the feeling of aftertaste to enjoy entertainment English.

\subsection{Singing while listening}

Recent brain science studies have further confirmed the fact that many educators and the world know that songs come into our minds in a different way from other media and are remembered for a long time. Singing stimulates our two hemispheres to learn, and mobilizes multiple intelligences to participate in it. English has its own singing characteristics, including vocal skills, the importance of rhythm and the fluctuation of melody. Mr. Tensor Guan of our country originated Singing English and achieved unexpected teaching effect with his unique and rigorous training strategy. Therefore, we searched and downloaded the lyrics and audio of many different styles of British and American songs, processed and produced them, and set up the Music column to facilitate teachers and students to teach and learn to sing. At the same time, we have also set up listening games Game, Radio and other online radio columns, so that our college students enjoy "Happy English" online through singing. The above basic strategies should be applied flexibly and integrated with reality. With the further development of research work and the development of multimedia network computer technology, we will better improve and apply the online listening training strategy of middle school English.

\section{CONCLUSIONS}

Language skills include listening, speaking, reading and writing. Listening comes first and is the basis for language learning. Listening ability directly influences the overall development of language ability. In a word, the improvement of English listening level is a long-term and gradual process, and also a process restricted by the comprehensive abilities of vocabulary, grammar, reading comprehension and knowledge. It is desirable for the proposed online listening training 
construction will be able to serve the majority of students.

\section{ACKNOWLEDGMENTS}

Author information: Lihua Tang, female (1979.4--), Han. Nanchong, Sichuan. Master's degree, Associate Professor, research field: English Teaching

The paper was supported by the Cooperation project between College of foreign languages Education of China West Normal University and Correction network (No. GPH21006).

\section{REFERENCES}

[1] Linda Woo. SHADOWING: A POWERFUL LISTENING

TOOL[DB/OL].http://www.lang.nagoya-u.ac.jp/bu nai/dep/eigog/listening/.

[2] Daolong Zhong My Way of Special English [DB/OL].

http://splayboy.myetang.com/eng/nieng.htm.

[3] Anxiang Xu. Reading Aloud Helps Language Learning

[DB/OL].http://www.allwinenghsh.com/hips/newsdetails.aspid $=78$

[4] Ministry of Education. Basic education curriculum reform - English curriculum standards for primary and secondary schools [DB/OL] http://www.english.ac.cn/oxford/index.htm.
[5] Aijun Liu, 2009, Research on listening and speaking teaching mode in Multimedia Network Environment [J], foreign language world (5): $63-64$.

[6] Liuheng, Zhen Zhinian, 2008, Study on English Listening Classroom Teaching of Higher Vocational Students' negotiating [J], Journal of Jixi University (5): 8.

[7] Kefu Lang, Wangling, 2010, Research on the motivation of autonomous learning under the Internet Teaching Model [J], foreign language world (3): 16.

[8] Dingfang Su, 2013, Comprehensive curriculum objectives and quality of English Majors -- a review of the third foreign language teaching competition held by the foreign teachers' Association Cup in China[J], foreign language world(2): 43-49.

[9] Dingfang Su, 2012, College English teaching competition and teacher development $[\mathrm{J}]$, foreign language world (3): 34-41.

[10] Junping Zhou, 2006, Teacher talk and second language acquisition $[\mathrm{J}]$, foreign language teaching (5): 69-73 